\title{
Assessment of Seroprevalence and the Risk Factors of Sheep Brucellosis in Basrah (Southern Iraq): A Challenge to Prospectively Control Brucellosis
}

\author{
Mohanad Faris Abdulhameed $^{1 *}$ (D), Moaed Hanoon Sayhood ${ }^{1}$ (D), \\ Ali Balbool Aldeewan ${ }^{2}$ and Tareq Hadi Srayyih ${ }^{3}$ (D) \\ ${ }^{1}$ Public Health Department, College of Veterinary Medicine, University of Basrah, Basrah, Iraq. \\ ${ }^{2}$ Microbiology and Parasitology Department, College of Veterinary Medicine, University of Basrah, Basrah, Iraq. \\ ${ }^{3}$ Internal and Preventive Medicine Department, College of Veterinary Medicine, University of Basrah, Basrah, \\ Iraq.
}

\begin{abstract}
Brucellosis is one of the most important foodborne infectious diseases distributed widely in low- and middle-income countries. The current study was carried out to investigate the prevalence and risk factors that influence the distribution of Brucella in sheep. A structured questionnaire was prepared and introduced to a total of 60 resident owners from five counties, and 400 sheep blood samples were randomly collected from the selected herds. The sera of isolated sheep were tested for Brucella spp. using the Rose Bengal Test (RBT). A univariable and multivariable logistic regression analysis was used to evaluate the risk factors linked to animal management and husbandry practices at the farm level. The overall prevalence estimated for brucellosis was 31\% (95\% confidence interval [Cl]: 26.5-35.8). The odds of seroprevalence in sheep $>1$ year were significantly higher than those in sheep $\leq 1$ year (odds ratio [OR]: $2.2,95 \% \mathrm{Cl}: 1.41-3.44$ ). The logistic regression outcomes revealed that two variables related to the management and practices at the farm level were significantly associated with the seroprevalence of brucellosis. These variables were sheep sheep grazing with other flocks (OR: 5.8, 95 $\mathrm{Cl} \% \mathrm{Cl}$ : 1.53-22.67) and the practice of lending ram among sheep owners (OR: 9.3, 95\% Cl: 1.05-83.82). Unconfined domesticated dogs, improper handling of aborted ewes, introduction of new animals in a herd, (purchased), and lack of knowledge about brucellosis among owners were underlined to be further important factors that could influence the spread of brucellosis. This study concluded that brucellosis is an endemic disease in Basrah, and the animal vaccination control program with an integrated health education program for sheep owners are obligatory elements of the prevention measures needed to be established to minimize the risk of brucellosis in Basrah.
\end{abstract}

Keywords: Seroprevalence of brucellosis, Risk factors, Questionnaire survey, Sheep owners, Basrah province

*Correspondence: Mohanad.Faris@Uobasrah.edu.iq; +96 47725822064

(Received: September 24, 2020; accepted: November 25, 2020)

Citation: Abdulhameed MF, Sayhood MH, Aldeewan AB, Srayyih TH. Assessment of Seroprevalence and the Risk Factors of Sheep Brucellosis in Basrah (Southern Iraq): A Challenge to Prospectively Control Brucellosis. J Pure Appl Microbiol. 2020;14(4): 2543-2554. doi: 10.22207/JPAM.14.4.30

(C) The Author(s) 2020. Open Access. This article is distributed under the terms of the Creative Commons Attribution 4.0 International License which permits unrestricted use, sharing, distribution, and reproduction in any medium, provided you give appropriate credit to the original author(s) and the source, provide a link to the Creative Commons license, and indicate if changes were made. 


\section{INTRODUCTION}

Brucellosis is a highly prevalent zoonosis disease in most parts of Asia and has a significant impact on human health and livestock production $\mathrm{s}^{1,2}$. It is caused by infection with bacteria belonging to the genus Brucella spp. The disease can infect a wide range of domesticated and wild animals. Brucella is transmitted between animals by direct or indirect contact with an infected animal through aborted fetuses, placenta, vaginal discharges, and fetal fluids, or or the transmission occurs vertically from ewes to lambs and ewes to rams or vice versa ${ }^{3}$. Brucellosis in animals results in significant economic burden because of abortion, decreased milk production, reduced reproduction rate, and premature births $s^{4-6}$. For instance, the median economic losses in India due to brucellosis in livestock were estimated at US \$ 3.4 billion $^{7}$. In contrast, on assumption, a cost benefit analysis for better intervention and implementation control program for cattle has been estimated at US $\$ 4.16$ to $\$ 8.31$ billion and for buffalo at US $\$ 7.66$ to $\$ 13.42$ billion, which resulted from a decrease in prevalence below $2 \%$ in 20 years of program intervention ${ }^{8}$. Brucellosis in humans is primarily associated with the consumption of unpasteurized dairy products or the direct contact with infectious material, particularly through occupational exposure in animal owners, slaughterhouse workers, and veterinarians ${ }^{5,9}$. Brucellosis in humans results in an acute or subacute intermittent fever clinically accompanied by malaise, fatigue, and anorexia. If left untreated, the disease may persist for days or months progressing into a chronic form ${ }^{10}$. Recovery from brucellosis in humans is possible with the use of efficient antimicrobial drugs such as streptomycin and doxycycline. Use of these drugs is recommended for more than 6 weeks ${ }^{11}$. Untreated cases could develop hepatomegaly, splenomegaly, endocarditis, and epididymoorchitis ${ }^{3,12,13}$. The treatment of infected animals is prolonged due of the intracellular growth of the pathogen ${ }^{14,15}$; hence, slaughtering cattle when they positive for brucellosis is a successful strategy for the ultimate eradication of the disease in animal populations ${ }^{1}$. Diagnosis of brucellosis sometimes is quite difficult due to a variety of clinical signs. The confirmatory diagnosis regime of the disease is often based on cultural or serological testing ${ }^{16}$, and the diagnostic tests have different purposes including confirmatory diagnosis, determination of prevalence, and surveillance ${ }^{1}$.

Several factors highlighted from previous epidemiological studies that influence the spread of the disease are linked to animal biosecurity, intermingling of animals with different herds at the shared water and grazing points, poor sanitation level of farms, introduction of new animals to herds (purchase), incorrect disposal of placenta and aborted fetuses, and absence of a vaccination control programme $\mathrm{e}^{17,18}$. Herd/flock size is considered as a potential factor for brucellosis, which increases the probability of transmission of the disease among animal populations ${ }^{19}$. The highest prevalence of brucellosis was reported in a large flock, as maintaining hygienic conditions in these flocks or routine cleaning and disinfection at the paddock by removal of manure and other filthy wastes required diligent work ${ }^{20}$. In addition, dogs are considered another important risk factor for the spread of brucellosis within/outside flocks. In particular, free-roaming dogs can play a critical role in the contamination of the environment through feeding upon infected aborted fetuses or dragging them to or near a grazing field ${ }^{20,21}$. Brucellosis in small ruminants remains a notifiable endemic disease in most parts of the Mediterranean region, the Middle East, Africa, and Asia ${ }^{22}$. In Iraq, the disease has been frequently reported in sheep and goats, with a prevalence estimated between $10 \%$ and $50 \%{ }^{23-25}$. Human brucellosis has been frequently reported in different provinces of Iraq, with the annual incidence of cases reported to have reached $2.4 \%$ per 100,00026 . Brucella melitensis was the predominant species identified ${ }^{27,28}$. Few epidemiological studies with insights into brucellosis distribution have been conducted at Basrah, one of the third largest provinces in Iraq. Therefore, this study aimed to determine the prevalence of brucellosis in sheep and identify risk factors by allocating a questionnaire to sheep owners in Basrah province.

\section{MATERIALS AND METHODS}

\section{Study area and sampling plan}

The field work was performed in the Basrah province, located in the south of Iraq (Fig. 1). The province has extremely hot weather during the summer season, with a mean temperature of $37.4^{\circ} \mathrm{C}$ and a maximum 
temperature of $45^{\circ} \mathrm{C}$. The lowest mean summer temperature was $29.2^{\circ} \mathrm{C}$. The annual humidity is less than $50 \%$ and remains below $30 \%$ during the daytime ${ }^{29}$. Basrah is not only famous for the its oil industry and resources, but it has also been recognized as a pastoral area with diversity of palm trees and a large number of animal species. The data from veterinary hospital records show a total of 79982 species of sheep, 6725 species of goats, 55151 species of cattle, and 54467 species of buffalo in the rural and peri-urban areas.

To determine the prevalence of brucellosis in sheep, an observational study was performed in Basrah province, using a multistage sampling method. The sampling period was between December 2019 to June 2020. Undeniably, the sampling processes in the present study were delayed and did not involve a large number of owners/sheep because of the coronavirus disease 2019 outbreak and some security matters. However, we ensured several safety precautions during visits to a study unit. There was no actual sampling frame available for the target sheep populations stored at the Basrah veterinary hospitals. Only the total number of sheep in the province regions was available. Hence, it was challenging to generate simple or systematic random samples. We adopted a convenient sampling method based on a participatory approach with the assistance of the farmers/chairman of clans/veterinarians who had knowledge and information about other farmer/ owner locations in each sub-county and village. All sheep flocks sampled were stratified according to the number of sheep into three flock size strata and then sampled accordingly: small flock (20-50 sheep $=2-3$ sheep samples), medium flock (50-100 $=10$ sheep samples), and large flock (>150 $=15$ sheep samples). A total of five out of seven counties in Basrah were sampled; two counties were excluded because they contained a small number of animals. Within each county, two sub-counties were randomly selected. From each sub-county, three villages were randomly selected. Two sheep owners from each village were invited to participate. The minimum number of samples were obtained from the sale yards of the Al-Zubair county 38 blood samples from 12 small herds ( 3 to 5 animals sampled from each herd). All owners involved in this study also agreed to allow access to their animals for blood collection. A total of 400 sheep blood samples were collected, and from each flock or farm, the animals were selected randomly either at every five steps or every third animal (systematic interval) was chosen when the animals ran through an open gateway of the barn. Then, each targeted animal was grabbed by the owner and held up or down for blood sample collection. As postulated, the number of samples collected in the current study received a sampling probability based on an expected prevalence of brucellosis in the region as $30 \%$, desired absolute precision of $5 \%$, and level of confidence of $95 \%{ }^{30}$. At the time of sampling, a questionnaire-based survey was conducted to identify risk factors associated with the sheep brucellosis, which is described in detail in the next subsection.

\section{Questionnaire allocation}

The questionnaire was allocated to the sheep owners to specifically collect information about risk factors that influence the spread of Brucella. The questionnaire is briefly outlined as follows: demographic characteristics of owners, ownership of dogs, chaining of dogs, flock grazing pattern, incidence of abortion, introduction of new animals in a herd, sources of water supply for herds, common usual diseases treated, knowledge of brucellosis, hygiene conditions and sanitation, vaccination against brucellosis, and the practice of lend a ram. Most of these questions were closeended questions with different forms of answers, including dichotomous, multiple choices, and ranking. The questionnaires were pre-tested on three animal owners before the actual survey was launched to determine content validity. The interviewers were familiarized with the questionnaire to avoid any misconceptions during the interviews. The owners were interviewed face-to-face, in coordination with the veterinary clinicians present in each district. A total of 60 sheep owners were involved in this study from the selected areas, and none of them refused to participate. All the owners were interviewed at their farm properties except from 12 owners from the Al-Zubair county, who were interviewed at sale yards, as aforementioned. The questionnaire was translated into Arabic. Prior to allocation of the questionnaire, the owners were asked for verbal consent to participate in the survey. 


\section{Collection and testing of the blood samples}

Blood samples were obtained from the animals of different ages and sexes randomly from each flock. The owners were requested to take over their animals to facilitate the collection of blood samples. The animal ages were determined by the dentition method. Blood samples $(5-10 \mathrm{~mL})$ were directly taken from the jugular vein of each individual animal and placed carefully at 90-degree angle in the sterilized test tubes to avoid instant clot formation. The samples were subsequently transferred via a cooling box to the microbiological lab at the College of Veterinary Medicine/ University of Basrah for diagnostic testing for Brucella. Separated serum samples were stored in sterile Eppendorf tubes. A serological test for screening of sera was carried out to identify the positive samples with Brucella spp. infection using the Rose Bengal Test (RBT).

\section{Data analyses}

The data were stored in an Excel sheet and analyzed using SPSS software (version 23). Univariable analysis was initially performed using a Chi-square test to determine an association between the dependent variable (seropositivity) and independent variables (factors related to animal characteristics and flock management practices). The outcome variables were binary with two possible categorical outcomes coded as 0 (no) and 1 (yes). Odds ratios (ORs) and their 95\% confidence intervals (Cls) were calculated using Woolf's method. Variables of $p \leq 0.05$ were considered significant and subsequently incorporated into a final logistic regression model. Variables that had model $p$ values (twosided) $\leq 0.25$ were retained for the multivariable analysis ${ }^{32}$. A backward-elimination procedure was used to determine the best model. Models were compared using the likelihood-ratio test. Although 10 variables were excluded from the regression, they were tabulated as descriptive modules using the exact binomial method (report-percentages and its $\mathrm{Cls}$ ). The seroprevalence combined with $95 \%$ confidence interval was calculated based on number of positive samples represented as the numerator divided by the total samples in the denominator.

\section{RESULTS}

Socio-demographic characteristics of owners

A total of 60 sheep owners were interviewed in this survey. The age distribution of the owners ranged from 21 to 82 years (mean $=48.33$, standard deviation $=14.33$ ) and majority of the animal owners were male $(98.3 \%)$ (Table 1). Regarding the education level of the owners, $46.6 \%$ of the owners had completed primary school and $26.7 \%$ of them were uneducated.

Seroprevalence of brucellosis in sheep according to sex, age, and county

Of the sheep sampled, $31 \%$ (95\% Cl: 26.5 , 35.8) tested positive for Brucella based on RBT test results. There was no significant difference between the seroprevalence in the female (34.3\%) and male (25.2\%) sheep (Table 2 ). The odds of seroprevalence in sheep aged $>1$ year were significantly higher than in sheep aged $\leq 1$ year (OR: $2.2,95 \% \mathrm{Cl}: 1.41,3.43$ ), $\mathrm{p} \leq 0.001, \chi 2=10.5$ ). Regarding the history of abortion in ewes, there were no significant differences observed between the ewes who had undergone abortion and the pregnant ewes that were infected with brucellosis. Overall, there was a significant difference in the seroprevalence test between the four counties $(p=0.01, \chi 2=10.5)$ as shown in Table 3. Only

Table 1. Descriptive analyses of socio demographic characteristics of the respondents (sheep owners)

\begin{tabular}{llll}
\hline Factor & Category & Frequency & Percentage $(95 \% \mathrm{Cl})$ \\
\hline Owner gender & Female & 1 & $1.7(0.0,9.0)$ \\
& Males & 59 & $98.3(91.1,100.0)$ \\
Education background & Never been in school & 16 & $26.7(16.1,39.7)$ \\
of owners & Literacy only & 4 & $6.7(1.9,16.2)$ \\
& Primary school & 28 & $46.6(33.6,59.9)$ \\
& Secondary school & 11 & $18.3(9.5,30.4)$ \\
& Tertiary level & 1 & $1.6(0.0,9.0)$
\end{tabular}


the Al-Zubair county has not been included in Table 3 because of the small sample size and the comparative bias between counties.

Association of seroprevalence of brucellosis with sheep management and practices at the farm level

Table 4 illustrates the univariable analysis and three variables that were identified with a $p$ value of $<0.05$ (sheep grazing outside, sheep grazing with other flocks, and the practice of lending rams among sheep owners). Ten variables are descriptively analyzed and summarized in Table 5. In this table, the majority of sheep owners owned dogs (25\%), and only $5 \%$ of them chained their dogs at their farm properties. Most of the sheep owners (33.3\%) indicated purchasing sheep (introducing new animals) from different counties of Basrah, while $21.7 \%$ bought sheep from the same counties where they lived. A total of $43.3 \%$ of the owners reported a number of abortions occurring among their sheep between the third and the fourth month of pregnancy; among those, $36.7 \%$ of the abortions resulted in stillborn fetuses. The owners reported 10 types of conditions/diseases occurring occasionally in their flock. Surprisingly, all the owners were unaware of brucellosis and its contagious nature.

A multivariable logistic regression analysis of animal management practices revealed that two variables were significantly associated with the seroprevalence of brucellosis in sheep, namely, sheep grazing with other flocks (OR: $5.8,95 \% \mathrm{Cl}$ : 1.53-22.67) and the practice of lending a ram among sheep owners (OR: 9.3, 95\% Cl: 1.05-83.82) (Table 6).

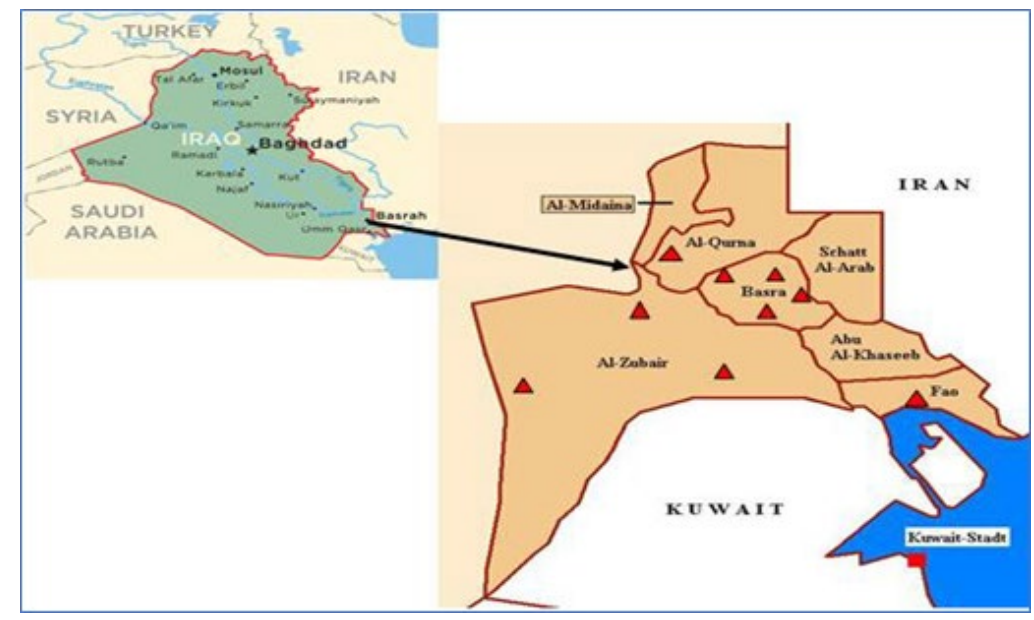

Fig. 1. Basrah province lies in southern Iraq map ${ }^{31}$.

Table 2. Animal characteristics factors associated with seropositivity of brucellosis in sheep

\begin{tabular}{|c|c|c|c|c|}
\hline Category & No. samples & No. positive (\%) & Odd ratio $(95 \% \mathrm{Cl})$ & p. value \\
\hline \multicolumn{5}{|c|}{ Animal sex } \\
\hline Female & 265 & $91(34.3)$ & $1.5(0.98,2.47)$ & 0.06 \\
\hline Male & 135 & $34(25.2)$ & 1.0 & \\
\hline \multicolumn{5}{|c|}{ Animal age group } \\
\hline$\leq 1$ year & 180 & $40(22.2)$ & 1.0 & $<0.001 * * *$ \\
\hline$>1$ years & 220 & $85(38.6)$ & $2.2(1.41,3.44)$ & \\
\hline \multicolumn{5}{|c|}{ History of abortion in ewes } \\
\hline Aborted & 54 & $26(48.1)$ & $2.0(0.89,4.82)$ & 0.08 \\
\hline Pregnant & 42 & $13(31.0)$ & 1.0 & \\
\hline
\end{tabular}

\footnotetext{
*** Significant factor with $\mathrm{p}$. value less than 0.05
} 
Table 3. Animal level apparent (test) seroprevalence of brucellosis in sheep in four counties

\begin{tabular}{lccccl}
\hline County & No. tested & No. positive & Prevalence $\%$ & $95 \% \mathrm{Cl}$ & p. value \\
\hline Abu-khaseeb & 88 & 15 & 17 & $9.8,26.5$ & $0.01^{*}$ \\
Al-Dyr & 80 & 25 & 31 & $21.1,42.3$ & \\
Al-Qurnah & 107 & 32 & 30 & $21.5,39.6$ & \\
Shatt-Alarab & 87 & 34 & 39 & $28.7,50.1$ & \\
\hline
\end{tabular}

* Significant factor with $p$. value less than 0.05 .

Table 4. Univariable analysis compared the association of the seroprevalence of Brucella and risk factors of animal practices and management adopted by owners

\begin{tabular}{|c|c|c|c|c|}
\hline \multirow[t]{2}{*}{ Factor } & \multicolumn{2}{|c|}{ Test results } & \multirow[t]{2}{*}{ Odd ratio $(95 \% \mathrm{Cl})$} & \multirow[t]{2}{*}{ p. value } \\
\hline & No. Positive & No. Negative & & \\
\hline \multicolumn{5}{|c|}{ Sheep grazing outside farm } \\
\hline Yes & $30(83.3)$ & $6(61.7)$ & $3.5(1.08,11.79)$ & 0.04 \\
\hline No & $14(58.3)$ & $10(41.7)$ & 1.0 & \\
\hline \multicolumn{5}{|c|}{ Sheep grazing with other flock } \\
\hline Yes & $27(87.1)$ & 4 (12.9) & $4.7(1.31,17.20)$ & 0.01 \\
\hline No & $17(58.6)$ & $12(41.4)$ & 1.0 & \\
\hline \multicolumn{5}{|c|}{ Dispose of the aborted foetuses and placenta } \\
\hline Throw away & $12(70.6)$ & $5(29.4)$ & $3.4(1.18,10.12)$ & 0.3 \\
\hline Throw in the river & $1(50.0)$ & $1(50.0)$ & $1.4(0.09,23.29)$ & \\
\hline Give to dog (s) & $7(100.0)$ & $0(00.0)$ & 1.0 & \\
\hline \multicolumn{5}{|l|}{ Call veterinarian } \\
\hline Yes & $24(75.0)$ & $8(25.0)$ & $1.2(0.38,3.77$ & 0.7 \\
\hline No & $20(71.4)$ & $8(28.6)$ & 1.0 & \\
\hline \multicolumn{5}{|c|}{ Purchased sheep in the last 12 months } \\
\hline Yes & $36(76.6)$ & $11(23.4)$ & $2.05(0.55,7.55)$ & \\
\hline No & $8(61.5)$ & $5(38.5)$ & 1.0 & 0.2 \\
\hline \multicolumn{5}{|l|}{ Source of water } \\
\hline Tape water & $27(73.0)$ & $10(27.0)$ & $1.3(0.11,16.57)$ & 0.9 \\
\hline River & $15(75.0)$ & $5(25.0)$ & $1.5(0.11,20.30)$ & \\
\hline Reverse osmosis water & $2(66.7)$ & $1(33.3)$ & 1.0 & \\
\hline \multicolumn{5}{|c|}{ Share these water sources } \\
\hline Yes & $23(82.1)$ & 5 (17.9) & $2.4(0.79,8.09)$ & 0.1 \\
\hline No & $21(65.6)$ & $11(34.4)$ & 1.0 & \\
\hline \multicolumn{5}{|c|}{ Vaccinated against brucellosis } \\
\hline No & $11(22.9)$ & $37(77.1)$ & $0.4(0.11,1.57)$ & 0.5 \\
\hline Not sure & $5(41.7)$ & $7(58.3)$ & 1.0 & \\
\hline \multicolumn{5}{|l|}{ Lend a male sheep (ram) } \\
\hline Yes & $14(93.3)$ & $1(6.7)$ & $7.0(0.84,58.40)$ & 0.04 \\
\hline No & $30(66.7)$ & $15(33.3)$ & & \\
\hline \multicolumn{5}{|c|}{ Clean and disinfected the barn } \\
\hline Yes & $38(70.4)$ & $6(100.0)$ & - & 0.1 \\
\hline No & $16(29.6)$ & $0(0.0)$ & & \\
\hline \multicolumn{5}{|l|}{ Frequent clean the barn } \\
\hline Every day & $16(54.5)$ & $5(45.5)$ & $0.4(0.03,5.15)$ & 0.3 \\
\hline Every week & $16(76.2)$ & $5(23.8)$ & $1.0(0.09,12.69)$ & \\
\hline Every month & $13(72.2)$ & $5(27.8)$ & $0.87(0.07,10.42)$ & \\
\hline Every year & $3(75.0)$ & $1(25.0)$ & 1.0 & \\
\hline
\end{tabular}




\section{DISCUSSION}

Brucellosis is one of the most important zoonotic diseases transmitted from animals to humans through different mechanisms, and the main target organs infected by Brucella are the reproductive systems of both males and females. This study aimed to assess the potential risk factors associated with seroprevalence of brucellosis in sheep. The information obtained from the current study would be eventually disclosed to the veterinary authority of Basrah, to aid in the preparation of brucellosis prevention programs. This is the first epidemiological study to screen for brucellosis among five counties of Basrah. Sheep and other ruminants are assumed to be the primary source of brucellosis infection in humans. Vaccination of young animals and elimination of infected animals are the best preliminary options

Table 5. Descriptive analysis of ten variables at the level of farm in Basrah province

\begin{tabular}{|c|c|c|}
\hline Question & Frequency & Percentage $(95 \% \mathrm{Cl})$ \\
\hline \multicolumn{3}{|l|}{ Do you own a dog (s)? } \\
\hline Yes & 15 & $25.0(14.7,37.9)$ \\
\hline No & 45 & $75.0(62.1,85.3)$ \\
\hline \multicolumn{3}{|l|}{ Do chain your dog? } \\
\hline Yes & 3 & $5.0(0.0,29.6)$ \\
\hline No & 12 & $20.0(4.3,48.1)$ \\
\hline \multicolumn{3}{|c|}{ If you purchased sheep where did they come from } \\
\hline Different county & 20 & $33.3(20.2,48.6)$ \\
\hline Same county different village & 13 & $21.7(11.0,36.1)$ \\
\hline Same county same village & 13 & $21.7(11.0,36.1)$ \\
\hline Different province & 1 & $1.7(0.0,10.6)$ \\
\hline \multicolumn{3}{|c|}{ Abortions in your sheep (ewe) during the last 12 months? } \\
\hline Yes & 26 & $43.3(30.3,56.4)$ \\
\hline No & 34 & $56.7(22.3,47.4)$ \\
\hline \multicolumn{3}{|c|}{ At what stage (month) did the abortions occur } \\
\hline Two months & 1 & $1.7(0.0,15.0)$ \\
\hline Three months & 16 & $26.7(4.7,35.6)$ \\
\hline Four months & 9 & $15.0(1.4,26.9)$ \\
\hline \multicolumn{3}{|c|}{ Did you isolate the aborted sheep from the rest of the flock? } \\
\hline Yes & 0 & $0.0(0.0,13.2)$ \\
\hline No & 26 & $43.0(23.9,63.7)$ \\
\hline \multicolumn{3}{|c|}{ Did all the abortions result in the birth of dead foetuses or did some survive for a period of time? } \\
\hline All died & 22 & $36.7(8.3,42.5)$ \\
\hline Some survived & 4 & $6.7(0.1,19.9)$ \\
\hline \multicolumn{3}{|c|}{ Main disease/ condition treated at your sheep? } \\
\hline 1-No diseases & 2 & $3.3(0.4,11.5)$ \\
\hline 2-Anti-worm (for intestinal parasites) & 17 & $28.3(17.4,41.4)$ \\
\hline 3-Diarrhoea & 13 & $21.7(12.1,(34.2)$ \\
\hline 4-Jaundice & 5 & $8.3(2.7,18.3)$ \\
\hline 5- Liver parasites & 1 & $1.7(0.0,9.0)$ \\
\hline 6-mange disease & 1 & $1.7(0.0 .9 .0)$ \\
\hline 7-Orf or Contagious Ecthyma & 8 & $13.3(5.9,24.6)$ \\
\hline 8- Respiratory infection & 11 & $18.3(9.5,30.4)$ \\
\hline 9-Sudden death & 1 & $1.7(0.0,9.0)$ \\
\hline 10-Tick infestation & 1 & $1.7(0.0,9.0)$ \\
\hline \multicolumn{3}{|c|}{ Have you heard of a disease called brucellosis? } \\
\hline Yes & 0 & $0.0(0.0,6.0)$ \\
\hline No & 60 & $100.0(94.0,100.0)$ \\
\hline
\end{tabular}


Table 6. Logistic regression results of association of significant factors (sheep management \& practices) with the seroprevalence of brucellosis

\begin{tabular}{lllll}
\hline Variable & $\beta^{*}$ & S.E.\# & p-value & Odds ratios $(95 \% \mathrm{Cl})$ \\
\hline Constant & 0.35 & 0.66 & 0.59 & - \\
Sheep grazing with other flock & 1.77 & 0.68 & 0.01 & $5.8(1.53,22.67)$ \\
Sheep not grazing with other flock & - & - & - & 1.0 \\
$\begin{array}{l}\text { Owners lend a sheep male (ram) from } \\
\text { other flock }\end{array}$ & 2.23 & 1.11 & 0.04 & $9.3(1.05,83.82$ \\
$\begin{array}{l}\text { Owners did not lend a sheep male } \\
\text { (ram) from other flock }\end{array}$ & - & - & - & 1.0 \\
\hline
\end{tabular}

as brucellosis control measures. Undoubtedly, the epidemiological information of brucellosis prior to establishment of the control program is necessary. Overall seroprevalence of $31 \%$ of sheep obtained in the present study was much higher than those reported in studies from the Kurdistan regions of northern Iraq. The data of seroprevalence for Sulaymani, Kirkuk, Dohuk, and Erbil were $7.9 \%, 6.9 \%, 4.9 \%$, and $8.1 \%$, respectively ${ }^{25}$. The seroprevalence tests in our study were also higher than those in other studies from Jordan and Egypt, which were estimated at $22.2 \%$ and $15.8 \%$, respectively ${ }^{33,34}$. It is worthwhile to postulate that the seroprevalence in the current study is very high, which may be due to inadequate hygiene level of the farm, intermingled grazing of different flocks, and an absence of preventative measures. Accordingly, national brucellosis control programs combined with mass vaccine campaigns were established in Iraq in 1996 and were continued after the war in 2003 with four vaccination campaigns introduced (2.1 million doses of Rev-1 vaccine and S19 doses of vaccine, types of vaccine used). Unfortunately, the campaigns stopped in $2010^{35}$. However, the seroprevalence between the counties of Basrah shows a significant difference. Basrah is an independent administrative territory; it is regionally an autonomous area linked commercially with other Iraqi provinces. Animals are traded freely without quarantine restrictions across the borders. Other reasons for the variations in the seroprevalence between or within the geographical areas could be associated with animal management practices, animal populations, and the sampling protocol adopted ${ }^{36,37}$.

The RBT technique is a widely recommended test to screen a large number of animals for brucellosis, as has been mentioned in several published epidemiological studies and surveillance programs ${ }^{38,39}$. However, the odds of seroprevalence in sheep aged $>1$ year were significantly higher than in sheep aged $\leq 1$ year (OR: $2.2,95 \% \mathrm{Cl}: 1.41-3.44)$. This finding is consistent with previous studies that indicated that the odds of infection with brucellosis can be significantly increased in adult sheep compared to young sheep $p^{33,40}$. The plausible inferences about this outcome could be that the adult animals are more susceptible subunits with a constant exposure to the etiological agent (Brucella spp.), particularly after puberty and pregnancy. In a meta-analysis study conducted by Tadesse ${ }^{41}$, it was found that the odds of the seroprevalence of brucellosis are increased by three times in post-pubertal animals than in pre-pubertal animals.

Based on the logistic regression outputs, animal grazing with other flocks (OR: $5.8,95 \% \mathrm{Cl}$ : 1.53-22.67) was found to be a significant risk factor associated with herd seroprevalence. The current result is in accordance with other studies ${ }^{42,43}$, which also indicated the importance of communal grazing in the seroprevalence of brucellosis. The probability of disease transmission to susceptible animals is considerably increased on allowing sheep to graze outside the farm or on adoption of a communal grazing pattern ${ }^{42}$.

Additionally, the logistic regression revealed that the owners who indulged in the practice of borrowing a ram from another owner were found to be significantly associated with brucellosis seropositivity (OR: $9.3,95 \% \mathrm{Cl}$ : 1.05-83.82). The practice of lending or exchanging rams among owners before or during breeding seasons (lambing season) was concluded to be one of the potential risk factors by other studies ${ }^{33,}$ 
44,45 . Farmers who wish to introduce a new animal to the flock should be required to get a health check-up done from a veterinarian along with rapid serological testing (using rapid kit test) before the introduction to ensure a healthy and fit flock.

Although there was no significant association between the history of abortions and the pregnancy status of ewes that were positive for brucellosis, contrasting results have been reported ${ }^{4,46}$. However, $43.3 \%$ of the respondents reported occurrence of a number of abortions among their animals between 3 and 4 months of gestation, most of them resulting in stillborn fetuses. To stress on this point, Brucella causes abortion in late pregnancy. This could be related to the tropism of Brucella to erythritol and a 4-carbon sugar that is produced in the fetal tissues of ruminants which then can stimulate the growth of Brucella ${ }^{47}$. Rapid replication of Brucella in uterine tissues causes alteration in the hormone levels through an increase in the amount of prostaglandin and a decrease in progesterone levels; consequently, abortion occurs during the third trimester of gestation ${ }^{48}$.

In addition, all the owners whose female animals had undergone abortions admitted that they had never isolated them from the rest of the herd. The animals who have had abortions carry pose a risk, originating from discharged fluids of the infected ewes (urine and uterus), to all other animals. They transmit the hazard to the healthy animals from different contaminated resources such as straws, troughs, and food stuffs ${ }^{49,} 50$. Thus, an education health program needs to be conducted for the animal owners to guide them for better handling of the aborted ewes and their separation from the rest of the herd.

Despite $25 \%$ of the sheep owners having a $\operatorname{dog}(s), 20 \%$ of their dogs were never chained. Unconfined dogs play an important role in the epidemiology of brucellosis, especially if control programs are not implemented in the region. Thus, vaccination for animals against brucellosis ${ }^{51}$ is important because unleashed/uncontrolled dog(s) usually can wander off and act as a mechanical disseminator or a carrier of the infection by fetching dead fetuses or placentas from abortions in the infected herd ${ }^{52}$. It is beneficial to recall that the majority of the owners in the current study admitted to mishandling of the aborted fetuses and placentas. A study from the Hamedan rural regions of Iran indicated that dogs play a crucial role in the transmission of Brucella to shepherds and livestock after screening of 180 unconfined domesticated dogs using RBT with a seroprevalence of brucellosis estimated at $3.3 \%{ }^{53}$. Therefore, it is important to educate owners or farmers regarding proper handling of the tissues of aborted ewes due to brucellosis by burning them or burying them in a secure place that is beyond the reach of unconfined dogs.

This study illustrates that the lack of knowledge about brucellosis and its mode of transmission could increase the possibility of the disease in the herds as well as in humans. This also supports the fact that the owners mentioned improper handling of aborted ewes and unsuitable disposal of dead fetuses and aborted placentas. The KAP (knowledge, attitudes, practices) questionnaire survey conducted in the Cape Province of South Africa and another survey conducted in two provinces of Pakistan (Punjab and Sindh) indicated that most of the animal owners had poor knowledge and low perception of brucellosis ${ }^{54,55}$. This supports an exigency for the integration of health education components in the disease control program with emphasis on periodic disease notifications and animal vaccination.

There were some limitations in to this study. It would be better if the enzymelinked immunosorbent assay (ELISA) technique, was used as a gold standard test to provide a more accurate estimation of the prevalence of brucellosis and eliminate false positive and negative results at a cut-off point. To develop a full picture of brucellosis, further studies are needed that include polymerase chain reaction (PCR) to confirm the species/strains/genotypes of Brucella spp. To obtain a better understanding of the epidemiological features of brucellosis in other animals (cattle, buffalo, and goats) and determine if these animals are additional reservoirs for Brucella, isolation and identification from cattle, buffalo, and goats need to be explored in a new study.

\section{CONCLUSIONS}

Brucellosis in sheep is a very important bacterial zoonosis disease. In the current study, the seroprevalence of brucellosis was very high in the sheep in Basrah. The results of 
this study highlighted that some factors of animal management practices were significantly associated with the seroprevalence of brucellosis, including grazing patterns and the prevalence of the practice of lending rams among sheep owners. Other important factors related to animal management and husbandry are also described in this study, for instance neglected chain dogs, improper handling of aborted ewes and their waste tissues, and ignoring the isolation of the infected aborted ewes from the healthy herd. Hence, an imperative intervention and preventative measures need to be undertaken through the establishment of mass vaccination campaigns to strengthen herd immunity levels. Additionally, an educational health program needs to be conducted for the sheep owners in conjunction with other measures in the control program.

\section{ACKNOWLEDGMENTS}

We would like to thank the college of Veterinary Medicine to give us an official permission to conduct this study in Basrah province. Our gratitude to the sheep owners who agreed to participate in this study.

\section{CONFLICT OF INTEREST}

All the authors declare that there is no conflict of interest.

\section{AUTHORS' CONTRIBUTION}

MFA was responsible for writing, analysis and editing the first draft. All authors conducted all the field work in Basrah province, samples collection and interview with the animal owners. All authors critically reviewed and approved the final version of the manuscript.

\section{FUNDING}

None.

\section{DATA AVAILABILITY}

The data involved in the current study are included in the manuscript and presented as Tables.

\section{ETHICS STATEMENT}

The study was obtained an approval agreement from the ethics research committee at the college of veterinary medicine/University of Basrah.

\section{REFERENCES}

1. Corbel MJ. Brucellosis in humans and animals. Geneva, Switzerland. World Health Organization; 2006.

2. Seleem MN, Boyle SM, Sriranganathan N. Brucellosis: A re-emerging zoonosis. Vet Microbiol. 2010;140(34):392-398. doi: 10.1016/j.vetmic.2009.06.021

3. Arenas-Gamboa AM, Rossetti CA, Chaki SP, GarciaGonzalez DG, Adams LG, Ficht TA. Human Brucellosis and Adverse Pregnancy Outcomes. Curr Trop Med Rep. 2016;3(4):164-172. doi: 10.1007/s40475-016-0092-0

4. Anka MS, Hassan L, Khairani-Bejo S, et al. A case-control study of risk factors for bovine brucellosis seropositivity in Peninsular Malaysia. PLoS ONE. 2014;9(9):e108673. doi: 10.1371/journal.pone.0108673

5. Franc KA, Krecek RC, Hasler BN, ArenasGamboacorresponding AM. Brucellosis remains a neglected disease in the developing world: a call for interdisciplinary action. BMC Public Health. 2018;18(125):1-9. doi: 10.1186/s12889-017-5016-y

6. Deka RP, Magnusson U, Grace D, Lindahl J. Bovine brucellosis: prevalence, risk factors, economic cost and control options with particular reference to Indiaa review. Infect Ecol Epidemiol. 2018;9(1):1-7. doi: 10.1080/20008686.2018.1556548

7. Singh BB, Dhand NK, Gill JP. Economic losses occurring due to brucellosis in Indian livestock populations. Prev Vet Med. 2015;119(3-4):211-215. doi: 10.1016/j. prevetmed.2015.03.013

8. Singh BB, Kostoulas P, Gill JPS, Dhand NK. Cost-benefit analysis of intervention policies for prevention and control of brucellosis in India. PLoS Negl Trop Dis. 2018;12(5):e0006488. doi: 10.1371/journal. pntd.0006488

9. Katafiasz AR, Bartett P. Motivation for Unpasteurized Milk Consumption in Michigan, 2011. Food Prot Trends. 2012;32(3):124-128.

10. Jia B, Zhang F, Lu Y, et al. The clinical features of 590 patients with brucellosis in Xinjiang, China with the emphasis on the treatment of complications. PLoS Negl Trop Dis. 2017;11(5):e0005577. doi: 10.1371/journal. pntd.0005577

11. Ariza J, Bosilkovski M, Cascio A, et al. Perspectives for the treatment of brucellosis in the $21 \mathrm{st}$ century: the loannina recommendations. PLOS Med. 2007;4(12):1872-1878. doi: 10.1371/journal. pmed.0040317

12. Rahil Al, Othman M, Ibrahim W, Mohamed MY. Brucellosis in Qatar: A retrospective cohort study. Qatar Med J. 2014;1:1-6. doi: 10.5339/qmj.2014.4

13. Akinci $E$, Bodur $H$, Cevik MA, et al. A complication of brucellosis: epididymoorchitis. Int J Infect Dis. 2006;10(2):171-177. doi: 10.1016/j.ijid.2005.02.006

14. Metcalf HE, Luchsinger DW, Ray WC. Handbook of zoonoses: section A. bacterial, rickettsial, chlamydial, and mycotic. 2 edition. Brucellosis. CRC Press; 1994.

15. Robinson DA. Guidelines for coordinated human and animal brucellosis surveillance. Rome, Italy: FAO: 2003:1-42. 
16. Rahman AK, Saegerman C, Berkvens D, et al. Bayesian estimation of true prevalence, sensitivity and specificity of indirect ELISA, Rose Bengal Test and Slow Agglutination Test for the diagnosis of brucellosis in sheep and goats in Bangladesh. Prev Vet Med. 2013;110(2):242-252. doi: 10.1016/j. prevetmed.2012.11.029

17. Megersa B, Biffa D, Abunna F, Regassa A, Godfroid J, Skjerve E. Seroprevalence of brucellosis and its contribution to abortion in cattle, camel, and goat kept under pastoral management in Borana, Ethiopia. Trop Anim Health Prod. 2011;43(3):651-656. doi: 10.1007/ s11250-010-9748-2

18. Bayasgalan C, Chultemdorj T, Roth F, et al. Risk factors of brucellosis seropositivity in Bactrian camels of Mongolia. BMC Vet Res. 2018;14(1):1-11. doi: 10.1186/ s12917-018-1664-0

19. Kabagambe EK, Elzer PH, Geaghan JP, Opuda-Asibo J, Scholl DT, Miller JE. Risk factors for Brucella seropositivity in goat herds in eastern and western Uganda. Prev Vet Med. 2001;52(2):91-108. doi: 10.1016/S0167-5877(01)00251-3

20. Coelho AM, Coelho AC, Roboredo M, Rodrigues J. A case-control study of risk factors for brucellosis seropositivity in Portuguese small ruminants herds. Prev Vet Med. 2007;82(3-4):291-301. doi: 10.1016/j. prevetmed.2007.06.001

21. Sammartino LE, Gil A, Elzer P. Capacity building for surveillance and control of bovine and caprine brucellosis. 2006:55-112. FAO Animal Production and Health Proceedings - AO/WHO/OIE Expert and Technical Consultation.

22. OIE. Animal Disease Information. Brucellosis. (Accessed on 28 December 2017). http://www.oie.int/fileadmin/ Home/eng/Media_Center/docs/pdf/Disease_cards/ BCLS-EN.pdf. 2006

23. Al-Tae AH, Al-Samarrae EA. Detection of Brucella Antibodies of Sheep in Al-Anbar Province by Using Some Serological Tests. Iraqi J Vet Med. 2013;1(37):712.

24. AL-Busultan AS, AL-Bassam LS, AL-Shididi AM, AL-Hashemi BM. Cross sectional study on the seroprevalence of brucellosis in sheep, goat and man in Diyala governorate. Mirror Res Vet Sci Anim. 2017;7(1):1-19.

25. Alshwanya EAA, Robertson ID. Epidemiology of Brucellosis in Sheep and Goats in the Iraqi Kurdistan Region. J Sci Technol. 2018;8(4):33-37.

26. Salman W, Al-Gburi NM. Incidence of Brucellosis in humans (Iraq 2006-2016). Vet Res. 2018;22(5):402408.

27. Amin BK, Hassan KI. Molecular Typing of Human Brucella melitensis Isolated from Patients in Erbil, Iraq. Sci J Koya Uni. 2019;7(1):1-4.

28. Sacchini L, Wahab T, Di Giannatale E, et al. Whole Genome Sequencing for Tracing Geographical Origin of Imported Cases of Human Brucellosis in Sweden. Microorganisms. 2019;7(10):1-17. doi: 10.3390/ microorganisms 7100398

29. Hadeel AS, Jabbar MT, Xiaoling C. Remote sensing and GIS application in the detection of environmental degradation indicators. Geo-spatial Inf Sci.
2011;14(1):39-47. doi: 10.1007/s11806-011-0441-z

30. Cannon RM, Roe RT. Livestock disease surveys- a field manual for veterinarians Bureau of Rural Science. ustralian Government Publishing Service, Canberra. 1982:35.

31. Al-Taie E, Al-Ansari N, Saaed TE, Knutsson S. Bearing Capacity Affecting the Design of Shallow Foundation in Various Regions of Iraq Using SAP200 \& SAFE softwares. J Earth Sci Geotechnical Engin. 2014;4(4):35-52.

32. Hosmer D, Lemeshow S. Applied Logistic Regression. Second ed. John Wiley and Sons Inc; 2000. doi: 10.1002/0471722146

33. Musallam II, Abo-Shehada M, Omar M, Guitian J. Crosssectional study of brucellosis in Jordan: Prevalence, risk factors and spatial distribution in small ruminants and cattle. Prev Vet Med. 2015;118(4):387-396. doi: 10.1016/j.prevetmed.2014.12.020

34. Abdelbaset AE, Abushahba MFN, Hamed MI, Rawy MS. Sero-diagnosis of brucellosis in sheep and humans in Assiut and El-Minya governorates, Egypt. Int J Vet Sci Med. 2019;6(Sup1):S63-S67. doi: 10.1016/j. ijvsm.2018.01.007

35. Salih H, M. S. Brucellosis in Iraq: Epidemiology, Present Status, and Challenges in Controlling the Disease. Kansas State University. 2010.

36. Gwida M, Al Dahouk S, Melzer F, Rosler U, Neubauer H, Tomaso H. Brucellosis - regionally emerging zoonotic disease? Croat Med J. 2010;51(4):289-295 doi: 10.3325/cmj.2010.51.289

37. Zeng J, Duoji C, Yuan Z, et al. Seroprevalence and risk factors for bovine brucellosis in domestic yaks (Bos grunniens) in Tibet, China. Trop Anim Health Prod. 2017;49(7):1339-1344. doi: 10.1007/s11250-0171331-7

38. Al-Griw HH, Kraim ES, Farhat ME, Perrett LL, Whatmore AM. Evidence of ongoing brucellosis in livestock animals in North West Libya. J Epidemiol Glob Health. 2017;7(4):285-288. doi: 10.1016/j.jegh.2017.09.001

39. Jamil T, Kasi KK, Melzer F, et al. Revisiting Brucellosis in Small Ruminants of Western Border Areas in Pakistan. Pathogens. 2020;9(11):1-10 doi: 10.3390/ pathogens9110929

40. Addis SA, Desalegn AY. Comparative Seroepidemiological Study of Brucellosis in Sheep under Smallholder Farming and Governmental Breeding Ranches of Central and North East Ethiopia. J Vet Med. 2018:1-12. doi: $10.1155 / 2018 / 7239156$

41. Tadesse G. Brucellosis Seropositivity in Animals and Humans in Ethiopia: A Meta-analysis. PLoS Neg/ Trop Dis. 2016;10(12):e0005236. doi: 10.1371/journal. pntd.0005006

42. Al-Talafhah AH, Lafi SQ, Al-Tarazi Y. Epidemiology of ovine brucellosis in Awassi sheep in Northern Jordan. Prev Vet Med. 2003;60(4):297-306. doi: 10.1016/ S0167-5877(03)00127-2

43. Al-Majali AM, Majok AA, Amarin NM, Al-Rawashdeh OF. Prevalence of, and risk factors for, brucellosis in Awassi sheep in Southern Jordan. Small Rumin Res. 2007;73(13):300-303. doi: 10.1016/j.smallrumres.2007.02.002 44. Reviriego FJ, Moreno MA, Dominquez L. Risk factors for brucellosis seroprevalence of sheep and goat flocks in Spain. Prev Vet Med. 2000;44(3-4):167-173. doi: 
10.1016/S0167-5877(00)00108-2

45. Jackson R, Pite L, Kennard R, et al. Survey of the seroprevalence of brucellosis in ruminants in Kosovo. Vet Rec. 2004;154(24):747-751. doi: 10.1136/ vr.154.24.747

46. Tulu D, Gojam A, Deresa B. Serological investigation of brucellosis and its asso- ciation with abortion in sheep and goats in selected districts of Jimma zone, southwestern Ethiopia. Ethiop Vet J 2020;24(1):15-33. https://dx.doi.org/10.4314/evj.v24i1.2

47. Coelho AC, Diez JG, Coelhom AM. Risk Factors for Brucella spp. in Domestic and Wild Animals. In: Baddour MM, ed. Updates on Brucellosis. Intech Open; 2015:31. doi: 10.5772/61325

48. Carvalho Neta AV, Mol JP, Xavier MN, Paixao TA, Lage AP, Santos RL. Pathogenesis of bovine brucellosis. Vet J. 2010;184(2):146-155. doi: 10.1016/j.tvjl.2009.04.010

49. Grillo MJ, Barberan M, Blasco JM. Transmission of Brucella melitensis from sheep to lambs. Vet Rec. 1997;140(23):602-605. doi: 10.1136/vr.140.23.602

50. Behroozikhah AM, Nejad RB, Amiri K, Bahonar AR. Identification at Biovar Level of Brucella Isolates
Causing Abortion in Small Ruminants of Iran. J Pathog. 2012:1-12. doi: 10.1155/2012/357235

51. Aguiar DM, Cavalcante GT, Labruna MB, et al. Risk factors and seroprevalence of Brucella spp. in cattle from western Amazon, Brazil. Arquivos do Instituto Biologico. 2007;74(4):301-305.

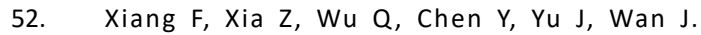
Seroepidemiology of canine brucellosis in Beijing, China. Turk J Vet Anim Sci. 2013;37(1):28-42.

53. Gharekhani J, Sazmand A. Detection of Brucella Antibodies in Dogs From Rural Regions of Hamedan, Iran. Avicenna J Clin Microbiol Infect. 2019;6(4):122126. doi: $10.34172 /$ ajcmi.2019.22

54. Arif S, Thomson PC, Hernandez-Jover M, McGill DM, Warriach HM, Heller J. Knowledge, attitudes and practices (KAP) relating to brucellosis in smallholder dairy farmers in two provinces in Pakistan. PLOS One. 2017;12(3):e0173365. doi: 10.1371/journal. pone. 0173365

55. Cloete A, Gerstenberg C, Mayet N, Tempia S. Brucellosis knowledge, attitudes and practices of a South African communal cattle keeper group. Onderstepoort J Vet Res. 2019;86(1):1-20. doi: 10.4102/ojvr.v86i1.1671 